\title{
The last erythrosuchid-a revision of Chalishevia cothurnata from the late Middle Triassic of European Russia
}

\author{
Richard J. Butler, Andrey G. Sennikov, Martín D. Ezcurra, and David J. Gower \\ Acta Palaeontologica Polonica 64 (4), 2019: 757-774 doi:https://doi.org/10.4202/app.00648.2019
}

Erythrosuchidae is a clade of early archosauriform reptiles that were large-bodied, hypercarnivorous, possibly apex predators in late Early and Middle Triassic ecosystems following the Permo-Triassic mass extinction. Chalishevia cothurnata from the late Middle Triassic (Ladinian) of Russia, is the stratigraphically youngest known erythrosuchid species, but the holotype and referred material of this taxon has received little study. Here, we provide the first detailed anatomical description of $C$. cothurnata, including comparisons to other erythrosuchids. Although known from relatively fragmentary material, the anatomy of $C$. cothurnata is distinctive, including an autapomorphic strongly slanted ventral border of the antorbital fossa. The presence of a large accessory opening (the "accessory antorbital fenestra") in the skull between the premaxilla, nasal and maxilla, together with the inferred presence of a narrow postnarial process of the premaxilla that articulated with a slot on the nasal, provides strong evidence for a sister taxon relationship between $C$. cothurnata and the erythrosuchid Shansisuchus shansisuchus from the early Middle Triassic (Anisian) of China. The inferred basal skull length of $C$. cothurnata was approximately $80 \mathrm{~cm}$, making it one of the largest erythrosuchids known.

Key words: Archosauriformes, Erythrosuchidae, anatomy, Triassic, Ladinian, Russia, Bukobay Gorizont.

Richard J. Butler [r.butler.1@bham.ac.uk], School of Geography, Earth and Environmental Sciences, University of Birmingham, Edgbaston, Birmingham B15 2TT, UK. Andrey G. Sennikov [sennikov@ paleo.ru], Borissiak Paleontological Institute RAS, Profsoyuznaya 123, Moscow 117647, Russia; Kazan Federal University, Institute of Geology and Petroleum Technologies, Kremlyovskaya str. 4, Kazan 420008, Russia. Martín D. Ezcurra [martindezcurra@yahoo.com.ar], School of Geography, Earth and Environmental Sciences, Univer-sity of Birmingham, Edgbaston, Birmingham B15 2TT, UK; Sección Paleontología de Vertebrados, CONICET-Museo Argentino de Ciencias Naturales "Bernardino Rivadavia”, Ángel Gallardo 470 (C1405DJR), Buenos Aires, Argentina. David J. Gower [d.gower@nhm.ac.uk], Department of Life Sciences, The Natural History Museum, London SW7 5BD, UK. 
This is an open-access article distributed under the terms of the Creative Commons

Attribution License (for details please see creativecommons.org), which permits unrestricted use, distribution, and reproduction in any medium, provided the original author and source are credited.

FaF Full text $(1,391.8 \mathrm{kB})$ 